\title{
Preventive effects of phenylethanol glycosides from Cistanche tubulosa on bovine serum albumin-induced hepatic fibrosis in rats
}

\author{
Shu-Ping You' ${ }^{1}$, Jun Zhao ${ }^{2,3}$, Long Ma', Mukaram Tudimat' ${ }^{1}$, Shi-Lei Zhang ${ }^{1}$ and Tao Liu ${ }^{1 *}$
}

\begin{abstract}
Background: Cistanche tubulosa is a traditional Chinese herbal medicine that is widely used for regulating immunity. Phenyl ethanol glycosides (CPhGs) from this plant are the primarily efficacious materials. This aim of this study was to evaluate the preventive and therapeutic effects of CPhGs on BSA-induced hepatic fibrosis in rats and related molecular mechanisms involving hepatic stellate cells. Biejiarangan (BJRG), another traditional Chinese herbal medicine, was used as a positive control.
\end{abstract}

Methods: In in vivo experiments, 75 SD rats were randomly divided into 6 groups: normal (distilled water-treated), model (BSA-treated), positive drug (BSA-treated + BJRG $600 \mathrm{mg} / \mathrm{kg} /$ day), and BSA-treated + CPhGs (125, 250, and $500 \mathrm{mg} / \mathrm{kg} /$ day) groups. The liver and spleen indices, serum levels of aspartate aminotransferase (AST), alanine aminotransferase (ALT), hexadecenoic acid (HA), laminin (LN), type III procollagen (PCIII), type IV collagen (IV-C), hydroxyproline (Hyp), and transforming growth factor $\beta_{1}$ (TGF- $\beta_{1}$ ) were measured in rat livers. Histopathological grades for liver fibrosis were assessed for each group using H\&E and Masson's trichrome staining. The expression of TGF- $\beta_{1}$, collagen I (Col-I) and collagen III (Col-III) were determined by an immunohistochemical staining method. These effects were further evaluated in vitro by determining expression levels of NF-kB p65 and Col-I by quantitative real-time PCR analyses. Col-I protein expression was also examined by western blotting.

Results: All dose groups $(125,250$, and $500 \mathrm{mg} / \mathrm{kg} /$ day) of CPhGs significantly reduced the liver and spleen index decreased ALT, AST, HA, LN, PCIII, IV-C serum levels, TGF- $\beta_{1}$ content $(P<0.01, P<0.01$, and $P<0.01)$, and Hyp content. CPhGs also markedly alleviated the swelling of liver cells and effectively prevented hepatocyte necrosis and inflammatory cell infiltration. Immunohistochemical results showed that CPhGs significantly reduced the expression of TGF- $\beta_{1}(P<0.01, P<0.01$, and $P<0.01)$, Col- I, and Col-III. The in vitro effects of CPhGs $(100,75,50$, and $25 \mathrm{ug} / \mathrm{ml})$ on HSC-T6 showed that CPhGs significantly reduced mRNA expression of NF-KB p65 and Col-I, and CPhGs also downregulated Col-I protein expression.

Conclusions: CPhGs have a significant anti-hepatic fibrosis effect, and may be used as hepatoprotective agents for treatment of hepatic fibrosis.

Keywords: Hepatic fibrosis, Cistanche tubulosas, Phenylethanol glycoside, Chemokine BSA, Prevention and therapy

\footnotetext{
* Correspondence: ximult@163.com

'Department of Toxicology, School of Public Health, Xinjiang Medical

University, No. 393 Xinyi Road, Urumqi 830011Xinjiang Uyghur Autonomous

Region, China

Full list of author information is available at the end of the article
} 


\section{Background}

Hepatic fibrosis is a wound healing response to severe liver injury that occurs in the pathogenesis of chronic hepatitis induced by various factors. These factors are viral infection, alcohol abuse, cholestasis, and metabolic and autoimmune diseases [1-3]. Progressive accumulation of extracellular matrix (ECM) and decreased remodeling disrupt the normal architecture of the liver, resulting in hepatic fibrosis [4]. Hepatic fibrosis is critical in chronic liver disease, and often develops into irreversible cirrhosis and carcinogenesis. At present, there are no methods or effective drugs for the treatment of hepatic fibrosis. Therefore, it is urgent to find an antihepatic fibrosis drug that will attenuate the progression of liver injury to fibrosis and cancer.

Cistanche tubulosa W (of the family Orobanchaceae) is a parasitic plant that is widely grown in the southern region of Xinjiang in China [5]. People usually use it to invigorate the kidneys, nourish the blood, relax the bowel, and delay senescence. It is officially listed in the Chinese Pharmacopoeia [6]. C. tubulosa contains a variety of active components. These include phenyl ethanol glycosides (CPhGs), iridoids, and polysaccharides. As one of many active components in C. tubulosa, CPhGs have exhibited convincing antioxidant, anti-fatigue, neuroprotective, and anti-inflammory effects in both in vivo and in vitro studies [7]. In recent years, it has been reported that CPhGs have hepatoprotective effects. Potential mechanisms underlying these effects are scavenging of free radicals, protection of hepatic membranes, immunoregulation, inhibition of apoptosis, inhibition of the expression of $\mathrm{HBsAg}$ and $\mathrm{HBeAg}$, and inhibition of HBV DNA replication and others [8-11]. However, few studies in the literature address the anti-hepatic fibrosis effect of GPhCs. Therefore, this study aimed to investigate the anti-hepatic fibrosis effect of GPhCs by using a model of bovine serum albumin (BSA) induced hepatic fibrosis in rats. Related molecular mechanisms were investigated in HSC-T6 cells.

\section{Methods}

\section{Chemicals and reagents}

A Hydroxyproline kit (Alkaline hydrolysis) (Lot: 20140616) was purchased from Nanjing Jiancheng Bioengineering Institute (China). Rat TGF- $\beta_{1}$ sandwich ELISA kits (Lot: 238240615) was purchased from Lianke Biotech Co., Ltd. (China). Rabbit Anti-Collagen I antibody (Lot: 140619), Rabbit Anti-Collagen III antibody (Lot: $980788 \mathrm{~W}$ ), and Rabbit Anti-TGF- $\beta_{1}$ antibody (Lot: 140619) were provided by Beijing Biosynthesis Biotechnology Co., LTD (China). Enclosed with normal sheep serum (working fluid) (Lot: WP141214), PV-6000 (Lot: WK141225), and DAB kit (Lot: K136621D) were purchased from Zhongshan Golden Bridge Bio-tech
Co., Ltd. (China). Detection of primary antibodies was performed by using 2. Antibody solution (Alk-Phos. Conjugated, Anti-rabbit) and 2. Antibody solution (Alk-Phos. Conjugated, Anti-mouse) (lot: 272387) purchased from Invitrogen company (USA).

Bovine serum albumin (BSA) (Lot: SLBG8239V) was purchased from Sigma (USA). Before use, BSA was prepared at $18 \mathrm{~g} / \mathrm{L}$ in normal saline, the bacteria removed by filtration, and BSA stored at $4{ }^{\circ} \mathrm{C}$. Freund's incomplete adjuvant containing $1 \mathrm{~g}$ of lipid from sheep hair (Lot: AF0220LA14, Shanghai yuanye Bio-Technology Co., Ltd. (China,) was mixed with 2 g liquid paraffin (Lot: 20130815, Tianjin Fuyu Fine Chemical Co., Ltd. (China,), sterilized in a steam autoclave, and stored at $4{ }^{\circ} \mathrm{C}$. The positive drug BJRG was obtained as Biejiarangan tablets from Inner Mongolia Furui Medical Science Co., Ltd. (China). BJRG drug stocks were prepared by dissolving BJRG tablets in distilled water at a concentration of $600 \mathrm{mg} / \mathrm{kg}$.

\section{Plant materials}

C. tubulosa (Orobanchaceae family) was purchased from the Minfeng region of Xinjiang of China. The material was authenticated by researcher Jun Zhao, Key Laboratory for Uighur Medicine, Institute of Materia Medica of Xinjiang. Voucher specimens were deposited in the Institute of Materia Medica of Xinjiang.

\section{Preparation of CPhGs}

Dried and sliced rhizomes of C. tubulosa $(6.0 \mathrm{~kg})$ were consecutively extracted under reflux three times with $70 \%$ ethanol, and the solvent was removed to yield the ethanol extract. Ethanol extracts were purified by using AB-8 resin to obtain the phenyl ethanol glycosides (CPhGs). Stock solutions of CPhGs used for different dose groups in animal studies $(500 \mathrm{mg} / \mathrm{kg}, 250 \mathrm{mg} / \mathrm{kg}$, and $125 \mathrm{mg} / \mathrm{kg}$, respectively) were dissolved in $0.5 \%$ (5 g/L) carboxymethyl cellulose (sodium salt).

\section{Quantification of CPhGs}

The contents of two components (echinacoside and acteoside) in the CPhGs were determined by HPLC using a previously reported method (Zhang et al. 2004) [12]. HPLC was performed by using a Shimadzu LC-10A HPLC equipped with a UV detector. The HPLC column was a Phenomenex Gemini ODS column $(250 \times 4.6 \mathrm{~mm}$, $5 \mu \mathrm{m})$. The isocratic mobile phase consisted of methanol-acetonitrile-1 \% acetic acid (15:10:75, v/v/v). Elution was for $40 \mathrm{~min}$ and the flow rate was kept at $0.6 \mathrm{~mL} / \mathrm{min}$. Column temperature was kept constant at $30{ }^{\circ} \mathrm{C}$. UV detection was at $334 \mathrm{~nm}$. 


\section{Animals and HSC-T6 cell line}

[Grade SPF] healthy adult male Sprague-Dawley (SD) rats $(180-220 \mathrm{~g})$ were purchased from Xinjiang Medical University Animal Center, License No.: SCXK (New) 2011-0004. Rats were fed specific-pathogen free (SPF) chow. All of the procedures related to the animal experiments were approved by the Animal Ethics Committee of First Affiliated Hospital of Xinjiang Medical University. Rats were housed in cages under controlled environmental conditions $\left(25^{\circ} \mathrm{C}\right.$ and a $12 \mathrm{~h}$ light/dark cycle) and had free access to standard rat pellet food and tap water. Rats were acclimated before treatment.

An immortalized rat hepatic stellate cell line, HSC-T6, was obtained from Wuhan Procell Gene Bio-technology Co., LTD. (Wuhan, China). HSC-T6 cells were cultured in Dulbecco's Modified Eagle's Medium (High Glucose) (DMEM, Beijing, China) supplemented with $10 \%$ fetal bovine serum (Gibco, South America), $100 \mathrm{IU} / \mathrm{ml}$ penicillin and $100 \mu \mathrm{g} / \mathrm{ml}$ streptomycin (Beijing, China) in a humidified incubator at $37{ }^{\circ} \mathrm{C}$ with $5 \% \mathrm{CO}_{2}$.

\section{BSA-induced liver injury and treatments}

Seventy-five SD rats were randomly divided into six groups: Normal (distilled water-treated), model (BSAtreated), positive drug (BSA-treated + BJRG $600 \mathrm{mg} / \mathrm{kg} /$ day), and BSA-treated + CPhGs $(125,250,500 \mathrm{mg} / \mathrm{kg} /$ day) groups. BSA-treated + CPhGs $(125,250,500 \mathrm{mg} /$ $\mathrm{kg} /$ day) groups had 13 rats in each group, and other group had 12 rats in each group. The BSA-induced liver injury model is divided into primary sensitization followed by immunological attack) [13]. Except for the normal group, the other groups were administered multiple subcutaneous injections with $0.5 \mathrm{ml}(9 \mathrm{mg} / \mathrm{ml})$ BSA Freund' incomplete adjuvant on day ${ }_{1}$, day ${ }_{15}$, day ${ }_{22}$, day 29 , and day ${ }_{36}$ for primary sensitization. Seven days after the fifth injection, blood was obtained through the rat retinal vein plexus and tested for serum albumin antibodies. BSA antibody in rat serum was detected by a double agar diffusion method. The attack injection was performed by administering $0.4 \mathrm{ml}$ of BSA in normal saline was through the caudal vein in BSA antibodypositive rats twice a week for ten times. The concentrations and times of injections were 5.00, 5.50, 6.00, 6.50, $7.00,7.50,8.50,9.00,9.50$ and $10.00 \mathrm{~g} / \mathrm{L}$ at day ${ }_{46}$, day ${ }_{50}$, day ${ }_{53}$, day ${ }_{57}$, day 60 , day ${ }_{64}$, day ${ }_{67}$, day ${ }_{71}$, day ${ }_{74}$ and day ${ }_{78}$, respectively. In the normal group, normal saline was used for immunological primary (sensitization) and secondary (attack) injections instead of BSA, and other conditions were the same as those in the model group.

The normal group was orally administered distilled water with dose $10 \mathrm{ml} / \mathrm{kg} /$ day. The model group was orally administered $10 \mathrm{ml} / \mathrm{kg} /$ day $0.5 \%$ CMC-Na solution. The positive drug group was orally administered $600 \mathrm{mg} / \mathrm{kg} /$ day BJRG. The BSA-treated + CPhGs (125,
250 , and $500 \mathrm{mg} / \mathrm{kg} /$ day) groups were orally administered 125, 250, and $500 \mathrm{mg} / \mathrm{kg} /$ day CPhGs, respectively. Daily dosing rats continued for two weeks after the last injection.

After the experimental period, rats were fasted for $12 \mathrm{~h}$ prior to $10 \%$ chloral hydrate and then immediately euthanized.. Serum samples were collected from each rat and immediately used. Livers were harvested for two purposes: (1) preservation in liquid nitrogen for Hyp kits and (2) fixation in $10 \%$ formaldehyde for histological and immunohistochemical examinations. The entire duration of the animal studies was 93 days.

\section{Liver and spleen indices}

The liver and spleen were dissected by laparotomy and washed with $4{ }^{\circ} \mathrm{C}$ normal saline. After absorbing excess water with filter paper, the liver and spleen were weighed to calculate the corresponding indices: Relative organ weight $=$ organ mass (g)/individual body mass $(\mathrm{g}) \times 100 \%$ [14] .

\section{Analysis of markers of liver fibrosis}

The protective effect of CPhGs against BSA-induced liver injury was evaluated by measuring ALT and AST (Mindray automatic biochemical analyzer,A086A0182). The development of liver fibrosis and effects of treatment were determined by examining HA, LN, PC III, and IV-C (Chemiluminescence analyzer,TaiGeKeXin, MP2808).

\section{Hyp content and TGF- $\beta_{1}$ analysis}

The level of Hyp in liver tissue was determined by a spectrophotometric method according to the kit's instructions. The level of Hyp was expressed as Hyp ( $\mu \mathrm{g}) /$ protein $(\mathrm{mg})$. Hyp $(\mu \mathrm{g} / \mathrm{mg})=\left(\right.$ Measured $\mathrm{OD}^{-}$blank $\left.\mathrm{OD}\right) /\left(\right.$ standard $\mathrm{OD}^{-}$ blank OD $) \times 5(\mu \mathrm{g} / \mathrm{ml}) \times 10 /$ tissue wet weight $(\mathrm{ml} / \mathrm{mg})$. The hepatic concentration of TGF- $\beta_{1}$ was detected by using ELISA kits according to the manufacturer's instructions. The inhibitory effect of CPhGs on fibrosis was confirmed by the expression levels of TGF- $\beta_{1}$.

\section{Histopathological examination}

The liver tissue in the same part of the left lobe was resected and fixed in $10 \%$ formaldehyde solution. Tissues were stained with conventional H\&E and Masson's trichrome staining to observe histopathological changes under a light microscope. Expression of collagen type I, collagen type III, and TGF- $\beta_{1}$ in liver tissues was analyzed by immunohistochemical staining [15].

Semi-quantitative immunohistochemistry was performed according to reported methods $[16,17]$. The following classifications were used for TGF- $\beta_{1}$ positive cells: "-" indicates almost no expression, $2^{0}=1$; " + " indicates positive cells individually gathered in the lesion area, $2^{1}=2$; " ++ " indicates positive cells in small groups 
gathered around the lesion area, $2^{2}=4 ;$ " +++ " indicates dispersed positive cells expressed, as $2^{3}=8$. The results represent a hierarchical integration. The collagen type I and collagen type III chromogenic degree and scope were converted into CRI for statistical analysis (chromogenic degree $\times$ chromogenic range). The chromogenic degree is divided into weak " + ", moderate " ++ " and strong "+++". The chromogenic range is divided into: "+", its chromogenic range < view $1 / 4$; "++", its chromogenic range of vision/4-2/4; " +++ ", its chromogenic range of vision 2/4-3/4; "++++", its chromogenic range $>3 / 4$. Blinded scoring was performed by two people where "+" is $1 ;$ " ++ " is 2 , " +++ " is 3 , and " ++++ " is 4 . Three microscope observational fields (magnification $\times 200$ ) were randomly selected for each section, with the average level of the samples used as a semi quantitative level.

\section{Cell experiments}

HSC-T6 cells were plated in a 96-well plate. Initially, cells were cultured with DMEM containing $10 \%$ FBS for $48 \mathrm{~h}$. The medium was then replaced with DMEM without FBS to starve the cells for $12 \mathrm{~h}$. The cells were then cultured with DMEM that contained $5.0 \mathrm{ng} / \mathrm{mL}$ TGF- $\beta_{1}$ (without FBS) for $24 \mathrm{~h}$. Finally, different concentrations of CPhGs (100ug/ml, 50ug/ml, and 25ug/ $\mathrm{ml})$, acteoside $(6 \mathrm{ug} / \mathrm{ml}, 3 \mathrm{ug} / \mathrm{ml}$, and $1.5 \mathrm{ug} / \mathrm{ml})$, and echinacoside (500ug/ml, $250 \mathrm{ug} / \mathrm{ml}$, and $125 \mathrm{ug} / \mathrm{ml}$ ) were carried out in the plate in qudruplicate wells and incubated for $48 \mathrm{~h}$.

\section{Real-time PCR analysis}

The mRNA expression level of NF- $\mathrm{kB}, \mathrm{p} 65$, and collagen I were determined by real-time PCR. To determine mRNA expressions in HSC-T6 cells, the cells $\left(4 \times 10^{5}\right.$ cells) were seeded in six-well plates with $3 \mathrm{~mL}$ DMEM with $10 \% \mathrm{FBS}$ and incubated overnight at $37{ }^{\circ} \mathrm{C}$ and $5 \%$ $\mathrm{CO}_{2}$, after which the cell culture media were changed to serum-free DMEM. Next, CPhGs $(100 \mathrm{ug} / \mathrm{ml}, 50 \mathrm{ug} / \mathrm{ml}$, and $25 \mathrm{ug} / \mathrm{ml})$, acteoside $(6 \mathrm{ug} / \mathrm{ml}, 3 \mathrm{ug} / \mathrm{ml}$, and $1.5 \mathrm{ug} /$ $\mathrm{ml}$ ), and echinacoside (500 ug/ml, $250 \mathrm{ug} / \mathrm{ml}$, and 125 $\mathrm{ug} / \mathrm{ml}$ ) were added to the wells. After $48 \mathrm{~h}$ of incubation with CPhGs or monomeric compositions, total RNA was extracted using TRIzol reagent (Invitrogen, USA) and agitated vigorously with chloroform for $15 \mathrm{~s}$. After sitting at room temperature for $3 \mathrm{~min}$, the lysate was centrifuged at $12,000 \times \mathrm{g}$ for $15 \mathrm{~min}$ at $4{ }^{\circ} \mathrm{C}$. RNA in the aqueous phase was precipitated with isopropanol, and the upper aqueous phase was transferred to a new microcentrifuge tube. RNA was precipitated by adding $0.75 \%$ ethanol, after which the microcentrifuge tube and centrifuged at $12,000 \times \mathrm{g}$ at $4{ }^{\circ} \mathrm{C}$ for no more than $5 \mathrm{~min}$. The supernatant was removed and the RNA was dried at room temperature for 5-10 min. Specific sets of primers (Sangon, Shanghai, China) that were used for amplification of rat $\beta$-actin [GenBank: NM_031144.3], Collagen I [GenBank: NM_ 053304.1], and NF-kB p65 [GenBank: NM_199267.2] genes were designed using Batch Primer 3. The forward (fw) and reverse (rv) primers were as follows: Collagen I (fw: GGA GAG AGC ATG ACC GAT GG, rv: GGG ACT TCT TGA GGT TGC CA), NF-кB p65 (fw: CAT ACG CTG ACC CTA GCC TG, rv: TTT CTT CAA TCC GGT GGC GA), $\beta$-actin (fw: TAA GGC CAA CCG TGA AAA GAT G, rv: AGA GGC ATA CAG GGA CAA CAC A). Results were normalized to the mRNA of the housekeeping gene $\beta$-actin as an internal control and are presented as relative mRNA levels.

Reactions were performed with $8 \mu \mathrm{L}$ iQ SYBR Green Supermix, $1 \mu \mathrm{L} 10 \mathrm{pM}$ primer pair, $8.5 \mu \mathrm{L}$ distilled water, and $2.5 \mu \mathrm{L}$ cDNA. Each polymerase chain reaction was performed under the following conditions: $95{ }^{\circ} \mathrm{C}$ for $3 \mathrm{~min}$, then 40 cycles of $10 \mathrm{~s}$ at $95{ }^{\circ} \mathrm{C}, 30 \mathrm{~s}$ at $55^{\circ} \mathrm{C}$, and $10 \mathrm{~s}$ at $55^{\circ} \mathrm{C}-95^{\circ} \mathrm{C}$ for extension, followed by a single fluorescence measurement. The final results were described with the relative values $\left(2^{-\Delta \Delta C t}\right)$. Calculation and analysis were performed by the iQ5 Real Time PCR Detection System.

\section{Western blot analysis}

Collagen I (Abcam, Cambridge, UK, Art No: ab34710) protein expression levels were determined by Western blotting [with $\beta$-actin (Lot: 60008-1-lg; Proteintech, China) as a housekeeping control. Whole cell extracts were prepared using Radioimmunoprecipitation assay (RIPA) (Thermo Scientific, USA) buffer with $1 \%$ Halt protease inhibitor cocktail (Thermo Scientific, USA) and $1 \%$ Halt phosphatase inhibitor cocktails (Thermo Scientific, USA). The protein concentration was measured and quantified by the Bradford method [18]. Protein (10-50 ug) was separated on a $10 \%$ SDS-PAGE gel and transferred to PVDF membranes (Millipore, USA). Membranes were blocked for $1 \mathrm{~h}$ at room temperature with $5 \% \mathrm{BSA}$, and the primary antibodies (Anti-Collagen I antibody, 1:200 dilution or mouse mAb of $\beta$-actin, 1:5000 dilution) were incubated at $4{ }^{\circ} \mathrm{C}$ overnight. The corresponding Alk-Phos. conjugated secondary antibodies were incubated at room temperature. Finally, the membranes were washed three times with $1 \times$ Tris $-\mathrm{HCl}$ saline with $0.1 \%$ Tween 20 , and signals were scanned and visualized by GEL DOC XR Imaging System (BioRad). Densitometric analysis was performed on the proteins of interest and normalized to $\beta$-actin by GEL DOC Image Studio software (Bio-Rad). $\beta$-actin was used as the internal control.

\section{Statistical analysis}

The Shapiro-Wilk normality test and Levene's variance homogeneity test were applied to verify normality and 
homogeneity of variance. Analysis of variance (ANOVA) followed by Tukey's post hoc test was used to identify statistical differences in homogeneous, normally distributed data. The Kruskal-Wallis non-parametric test was used to analyze data not normally distributed or homogeneous. Results were expressed as mean \pm SD. Significance was set at $P<0.05$. All data were analyzed by SPSS 16.0 software (Xinjiang Medical University).

\section{Results}

\section{Quantitative determination of CPhGs}

CPhGs in C. tubulosa contains two phenylethyl alcohol glycosides, echinacoside and acteoside, and their contents in the CPhGs were determined by HPLC analysis (Fig. 1) to be $42.71 \pm 0.42 \%$ and $14.27 \pm 0.18 \%$, respectively.

\section{Liver and spleen indices}

As Table 1 was shown, the liver and spleen indices of the model group were elevated significantly $[P<0.01$, $P<0.05]$. The liver and spleen indices of the positive drug BJRG and CPhGs at different dose groups were significantly reduced compared with the model group $\left[P_{\text {Liver }}=0.004, \quad P_{\text {Liver }}=0.003, \quad P_{\text {Liver }}=0.004, \quad P_{\text {Liver }}=\right.$ $0.005 ; \quad P_{\text {Spleen }}=0.017, \quad P_{\text {Spleen }}=0.027, \quad P_{\text {Spleen }}=0.024$, $P_{\text {Spleen }}=0.070$, respectively]. The liver and spleen indices were lower than those of the model group.

\section{Effects of CPhGs on ALT, AST activities and liver fibrosis markers}

In the present study, the serum levels of the hepatic enzymes AST and ALT were significantly increased in the model group, reflecting hepatocellular damage in BSAinduced liver fibrosis rats. However, the experiments
Table 1 Effects of CPhGs on the liver and spleen indices of hepatic fibrosis rats

\begin{tabular}{lllll}
\hline Group & Dose $(\mathrm{mg} / \mathrm{kg} /$ day) & $\mathrm{n}$ & Liver index (\%) & Spleen index (\%) \\
\hline Normal & - & 12 & $2.21 \pm 0.077^{* *}$ & $0.15 \pm 0.010^{* *}$ \\
Model & - & 11 & $2.65 \pm 0.245$ & $0.19 \pm 0.025$ \\
BJRG & 600 & 10 & $2.21 \pm 0.253^{* *}$ & $0.17 \pm 0.013^{*}$ \\
CPhGs & 500 & 12 & $2.32 \pm 0.153^{* *}$ & $0.16 \pm 0.025^{*}$ \\
& 250 & 9 & $2.40 \pm 0.150^{* *}$ & $0.16 \pm 0.017^{*}$ \\
& 125 & 10 & $2.39 \pm 0.103^{* *}$ & $0.16 \pm 0.033$ \\
\hline
\end{tabular}

Values are expressed as mean $\pm \mathrm{SD}, n=$ Survival number of animals ${ }^{*} P<0.05$, Compared with the model group; ${ }^{* *} P<0.01$, Compared with the model group

showed that treatment with BJRG $(600 \mathrm{mg} / \mathrm{kg})$ and $\mathrm{CPhGs}$ $(125,250$, and $500 \mathrm{mg} / \mathrm{kg})$ significantly reduced AST $\left[P_{\mathrm{AST}}<0.001, P_{\mathrm{AST}}<0.001, P_{\mathrm{AST}}<0.001, P_{\mathrm{AST}}<0.001\right.$, respectively $]$ and ALT $\left[P_{\mathrm{ALT}}=0.117, P_{\mathrm{ALT}}=0.139, P_{\mathrm{ALT}}=\right.$ $0.189, P_{\mathrm{ALT}}=0.255$, respectively] levels in hepatic fibrosis rats. (Table 2).

The levels of HA, LN, PC and IV-C in model rats were significantly increased $\left[P_{\mathrm{HA}}<0.001, P_{\mathrm{LN}}<0.001, P_{\mathrm{PCIII}}=\right.$ $0.002, P_{\mathrm{IV}-\mathrm{C}}<0.001$, respectively]. Compared with the model group, the levels of HA $\left[P_{\mathrm{HA}}=0.009, P_{\mathrm{HA}}=0.007\right.$, $P_{\mathrm{HA}}=0.009, P_{\mathrm{HA}}=0.023$, respectively $], \mathrm{LN}\left[P_{\mathrm{LN}}=0.011, P\right.$ LN $=0.004, P_{\mathrm{LN}}=0.026, P_{\mathrm{LN}}=0.069$, respectively $]$, PC III $\left[P_{\text {PCIII }}=0.006, P_{\text {PCIII }}=0.067, P_{\text {PCIII }}=0.136, P_{\text {PCIII }}=\right.$ 0.296 , respectively $]$, and IV-C $\left[P_{\text {IV-C }}<0.001, P_{\text {IV-C }}<0.001\right.$, $P_{\text {IV-C }}<0.001, P_{\text {IV-C }}<0.001$, respectively] in rats were markedly decreased by BJRG $(600 \mathrm{mg} / \mathrm{kg})$ and $\mathrm{CPhGs}$ at different dose groups $(125,250$, and $500 \mathrm{mg} / \mathrm{kg}$ ) (Table 3).

\section{Hyp content and TGF- $\beta_{1}$}

Collagen content was also detected by measuring Hyp levels in liver tissue. As shown in Table 4, the mean Hyp

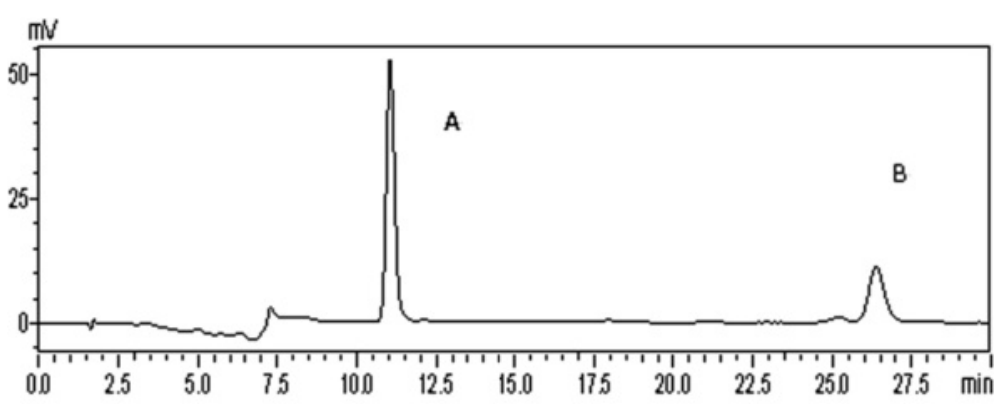

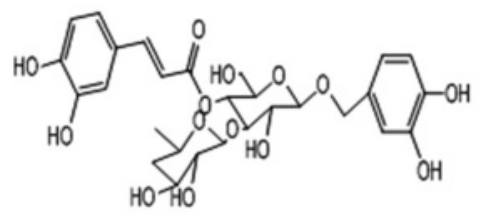

Echinacoside

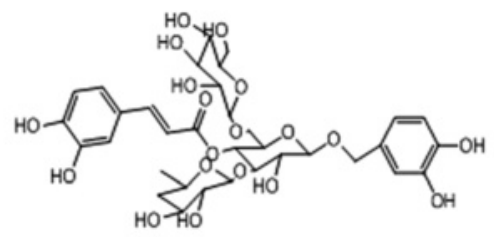

Acteoside

Fig. 1 The HPLC analysis of CPhGs and two phenylethyl alcohol glycosides, echinacoside and acteoside 
Table 2 Effects of CPhGs on the serum AST, ALT activities of hepatic fibrosis rats

\begin{tabular}{lllll}
\hline Group & Dose $(\mathrm{mg} / \mathrm{kg} /$ day $)$ & $\mathrm{n}$ & $\mathrm{ALT}(\mathrm{U} / \mathrm{L})$ & $\mathrm{AST}(\mathrm{U} / \mathrm{L})$ \\
\hline Normal & - & 12 & $38.12 \pm 2.789^{* *}$ & $77.82 \pm 16.675^{* *}$ \\
Model & - & 11 & $46.26 \pm 6.904$ & $173.27 \pm 27.389$ \\
BJRG & 600 & 10 & $39.68 \pm 6.716$ & $104.65 \pm 8.891^{* *}$ \\
CPhGs & 500 & 12 & $39.69 \pm 7.048$ & $105.23 \pm 8.865^{* *}$ \\
& 250 & 9 & $39.98 \pm 5.476$ & $106.60 \pm 20.270^{* *}$ \\
& 125 & 10 & $40.95 \pm 3.920$ & $119.72 \pm 25.368^{* *}$ \\
\hline
\end{tabular}

Values are expressed as mean $\pm \mathrm{SD}, n=$ Survival number of animals

${ }^{* *} P<0.01$, Compared with the model group

level in the model group was significantly higher than the normal group, but it was markedly decreased in the BJRG group and the different CPhGs dose groups.

The hepatic concentration of TGF- $\beta_{1}$ of the model group in rats was significantly increased $[P<0.001]$. Compared with the model group, TGF- $\beta_{1}$ levels of the positive drug and the different $\mathrm{CPhGs}$ dose groups were markedly decreased $[P$ TGF- $\beta 1<0.001, P$ TGF- $\beta 1<0.001$, $P_{\text {TGF- } \beta 1}<0.001, P_{\text {TGF- } \beta 1}<0.001$, respectively]. The results are summarized in Table 4.

\section{Histopathological examination}

Observations of normal liver tissue sections stained with $H \& E$ and Masson's trichrome exhibit distinct hepatic lobules and hepatic sinusoids. The liver tissue structure in the model rats was disordered, and the liver tissue and hepatic sinusoids were replaced by a large amount of connective tissue. However, more normal cytoarchitechture and less connective tissue were detected in the treatment group than those in the model group.

\section{H\&E staining}

In the normal group, hepatic lobule structural integrity without abnormal portal areas and hepatic sinusoids was observed. The hepatic cords were arranged in an orderly fashion, with the core round and clear. The nuclei are located in the central of the cell, with abundant cytoplasm. Only the portal area has a small amount of fibrous tissue (Fig. 2a).
Table 4 Effects of CPhGs on the Hyp content and TGF- $\beta_{1}$ of hepatic fibrosis rats

\begin{tabular}{lllll}
\hline Group & Dose $(\mathrm{mg} / \mathrm{kg} / \mathrm{day})$ & $\mathrm{n}$ & Hyp $(\mu \mathrm{g} / \mathrm{mg})$ & TGF $-\beta_{1}(\mathrm{ng} / \mathrm{ml})$ \\
\hline Normal & - & 12 & $125.61 \pm 57.118^{*}$ & $16.58 \pm 2.814^{* *}$ \\
Model & - & 11 & $196.70 \pm 82.545$ & $31.24 \pm 6.726$ \\
BJRG & 600 & 10 & $129.57 \pm 36.806$ & $20.16 \pm 4.638^{* *}$ \\
CPhGs & 500 & 12 & $132.77 \pm 50.705$ & $21.75 \pm 3.711^{* *}$ \\
& 250 & 9 & $134.99 \pm 64.824$ & $22.93 \pm 3.576^{* *}$ \\
& 125 & 10 & $139.14 \pm 41.352$ & $23.03 \pm 4.212^{* *}$ \\
\hline
\end{tabular}

Values are expressed as mean $\pm \mathrm{SD}, n=$ Survival number of animals ${ }^{*} P<0.05$, Compared with the model group; ${ }^{* *} P<0.01$, Compared with the model group

In the model group, the lobular structure was severely damaged. Liver cells showed mild watery degeneration, mostly ballooning degeneration and/or fatty degeneration. The formation of inflammatory cell infiltration, extensive fibrous tissue hyperplasia, the formation of a large number of fibrous septum, split lobules, and significant liver cells proliferation were also observed. These observations confirmed the success of the establishment of the rat immune injury animal model of hepatic fibrosis (Fig. 2b).

Compared with the model group, there was reduction in inflammatory cell infiltration in the different CPhGs. Also observed were less necrosis and fatty degeneration of liver cells as well as alleviation of fibrosis. CPhGs significantly mitigated the pathology of BSA-induced hepatic fibrosis in rats, alleviated the swelling of liver cells, and effectively prevented hepatocyte necrosis and inflammatory cells infiltration, suggesting that CPhGs exert protective effect on BSA -induced rat hepatic fibrosis. (Fig. 2c-f).

\section{Masson's trichrome staining}

In the normal group, the liver tissue was normal. The hepatic portal area showed a small amount of blue collagen fibers, and the liver tissue was normally structured (Fig. 3a). Compared with the liver tissue of the normal group, fibrous tissue proliferated by the central leaflet and expanded into the liver parenchyma. Collagen fibers extended and linked and

Table 3 Effects of CPhGs on the serum HA, LN, PCIII, IV-C activities of hepatic fibrosis rats

\begin{tabular}{lllllll}
\hline Group & Dose $(\mathrm{mg} / \mathrm{kg} / \mathrm{day})$ & $\mathrm{n}$ & $\mathrm{HA}(\mathrm{mg} / \mathrm{l})$ & $\mathrm{LN}(\mathrm{mg} / \mathrm{l})$ & $\mathrm{PCIII}(\mathrm{mg} / \mathrm{l})$ & $\mathrm{IV}-\mathrm{C}(\mathrm{mg} / \mathrm{l})$ \\
\hline Normal & - & 12 & $98.67 \pm 15.798^{* *}$ & $21.27 \pm 3.003^{* *}$ & $12.69 \pm 6.525^{* *}$ & $1.99 \pm 0.691^{* *}$ \\
Model & - & 11 & $116.08 \pm 7.683$ & $29.38 \pm 4.716$ & $33.87 \pm 16.336$ & $8.10 \pm 0.369$ \\
BJRG & 600 & 10 & $106.85 \pm 7.650^{* *}$ & $23.35 \pm 3.106^{*}$ & $21.09 \pm 7.113$ & $2.16 \pm 0.603^{* *}$ \\
CPhGs & 500 & 12 & $104.97 \pm 9.139^{* *}$ & $23.91 \pm 5.945^{*}$ & $23.58 \pm 8.815$ & $2.52 \pm 0.464^{* *}$ \\
& 250 & 9 & $106.19 \pm 6.250^{* *}$ & $24.12 \pm 3.593^{*}$ & $24.07 \pm 11.859$ & $3.10 \pm 0.692^{* *}$ \\
& 125 & 10 & $108.11 \pm 8.261^{*}$ & $25.41 \pm 4.925$ & $21.79 \pm 7.877$ & $3.39 \pm 0.980^{* *}$ \\
\hline
\end{tabular}

Values are expressed as mean $\pm \mathrm{SD}, n=$ Survival number of animals

${ }^{*} P<0.05$, Compared with the model group; ${ }^{* *} P<0.01$, Compared with the model group 
enveloped the entire lobule and surrounded the central vein. These effects, along with hepatocyte fibrosis, lobular structural damage, periportal fibrosis, and pseudolobule formation (Fig. 3b) provided evidence that the model was established.

Compared with the model group, the collagen fibers in the positive drug control group were mildly extended outward from the peripheral portal area (Fig. 3c). Compared with the model group, the collagen fibers in the different $\mathrm{CPhGs}$ dose groups were significantly reduced, fiber proliferation was inhibited, and proliferation of fibrous tissue within the liver parenchyma significantly reduced. These results suggested that $\mathrm{CPhGs}$ protected rats from BSA-induced hepatic fibrosis (Fig. 3d-f).

\section{Immunohistochemical staining}

Importantly, the expression of collagen type I and collagen type III play essential roles in the development of hepatic fibrosis, and their generation and deposition in the liver tissue could serve as an important determinant of the anti-hepatic fibrosis efficacy. The results are summarized in Table 5.

\section{Collagen type I}

The normal group expressed collagen type I mainly in blood vessels and the portal area. The model group highly expressed collagen type I vascular fibrosis in portal areas. In the space of Disse, collagen type I staining was observed a streaks or as a patchy distribution. Collagen encased fibrous septa to form pseudolobule. In these experiments, fewer fibrous septa were formed for BJRJ $(600 \mathrm{mg} / \mathrm{kg})$ and different dose groups of CPhGs s $(125,250$, and $500 \mathrm{mg} / \mathrm{kg})\left[\mathrm{P}_{\mathrm{Col} \mathrm{I}}\right.$ $=0.002, \mathrm{P}_{\mathrm{Col} \mathrm{I}}=0.001, \mathrm{P}_{\mathrm{Col} \mathrm{I}}=0.023$, and $\mathrm{P}_{\mathrm{Col} \mathrm{I}}=0.044$, respectively]. The semiquantitative results revealed that the expression of their collagen type I was significantly lower compared with the model group (Fig. 4).

\section{Collagen type III}

Collagen type III was weakly expressed in the normal group, and peripheral areas surrounding the portal and hepatic veins displayed a small amount of fine yellow instead of continuous fibers (Fig. 5a). In the model group, collagen fibers exhibited wide and thick cords, indicating strong expression, mainly located in the portal and fibrous tissue areas (Fig. 5b).

Collagen fibers of BJRJ $(600 \mathrm{mg} / \mathrm{kg})$ and different dose groups of CPhGs $(125,250$, and $500 \mathrm{mg} / \mathrm{kg})$ were filamentous and distributed around the central vein and portal areas. Compared with the model group, the collagen fibers were significantly reduced, staining was pale and thin, and immunohistochemical staining was weakly positive (Fig. $5 \mathrm{c}-\mathrm{f}$ ). These semi quantitative results show that the positively expressed cells in the positive and different dose groups $\left[P_{\mathrm{Col} \mathrm{III}}=0.015, P_{\mathrm{Col} \mathrm{III}}=0.001, P_{\mathrm{Col}}\right.$ III $=0.010$, and $P_{\mathrm{Col} \mathrm{III}}=0.037$, respectively $]$ were different from those in the model group.

\section{TGF- $\beta_{1}$}

There was little expression ofTGF- $\beta_{1}$ in normal rat liver cells. Expression was limited to a small number of interstitial cells (Fig. 6a). In the model group, TGF- $\beta_{1}$ expression was widely distributed in the portal area, fibrous spaces, hepatic stellate cells, inflammatory cells, the sinusoidal wall and cytoplasm. Aparticular portal area exhibited a strongly positive expression with brownish yellow staining (Fig. 6b).

There was a small amount of expression in the portal area and fibrous septa of BJRJ $(600 \mathrm{mg} / \mathrm{kg})$ and different dose groups of CPhGs (125, 250, and $500 \mathrm{mg} / \mathrm{kg}$ ). The extent of positive staining in these groups was significantly reduced compared with that of the model group. Staining in the interstitial cells in the fibrous septa and the cytoplasm of inflammatory cells was decreased (Fig. 6c-f). Semi quantitative results revealed that BJRJ and different dose groups of CPhGs $[P$ TgF $-\beta 1=0.001, P$ TGF $-\beta 1<0.001, P$ TGF $\beta 1=$ $0.009, P_{\text {TGF }-\beta 1}=0.004$, respectively] were significant compared with the model group.

As mentioned earlier in the article, TGF- $\beta_{1}$ is an important cytokine in the pathophysiology of liver

Table 5 The immunohistochemical staining intensity of Collagen type I, Collagen type III and TGF- $\beta 1$ i n BSA-induced hepatic fibrosis rats

\begin{tabular}{|c|c|c|c|c|c|c|c|c|c|c|c|c|c|c|}
\hline \multirow[t]{2}{*}{ Group } & \multirow{2}{*}{$\begin{array}{l}\text { Dose (mg/ } \\
\text { kg/day) }\end{array}$} & \multirow[t]{2}{*}{$n$} & \multicolumn{4}{|c|}{ Collagen type I } & \multicolumn{4}{|c|}{ Collagen type III } & \multicolumn{4}{|c|}{ TGF- $\beta 1$} \\
\hline & & & + & ++ & +++ & ++++ & + & ++ & +++ & ++++ & - & + & ++ & +++ \\
\hline Normal & - & 12 & 11 & 1 & 0 & 0 & 10 & 2 & 0 & 0 & 12 & 0 & 0 & 0 \\
\hline Model & - & 11 & 0 & 1 & 1 & 9 & 0 & 1 & 2 & 8 & 0 & 1 & 1 & 9 \\
\hline BJRG & 600 & 10 & 2 & 4 & 4 & 0 & 2 & 4 & 3 & 1 & 2 & 5 & 3 & 0 \\
\hline \multirow[t]{3}{*}{ CPhGs } & 500 & 12 & 3 & 5 & 3 & 1 & 4 & 4 & 3 & 1 & 3 & 6 & 2 & 1 \\
\hline & 250 & 9 & 1 & 4 & 3 & 1 & 2 & 4 & 2 & 1 & 1 & 5 & 2 & 1 \\
\hline & 125 & 10 & 1 & 5 & 1 & 3 & 1 & 5 & 3 & 1 & 2 & 4 & 3 & 1 \\
\hline Total & & 64 & 18 & 20 & 12 & 14 & 19 & 20 & 13 & 12 & 20 & 21 & 11 & 12 \\
\hline
\end{tabular}




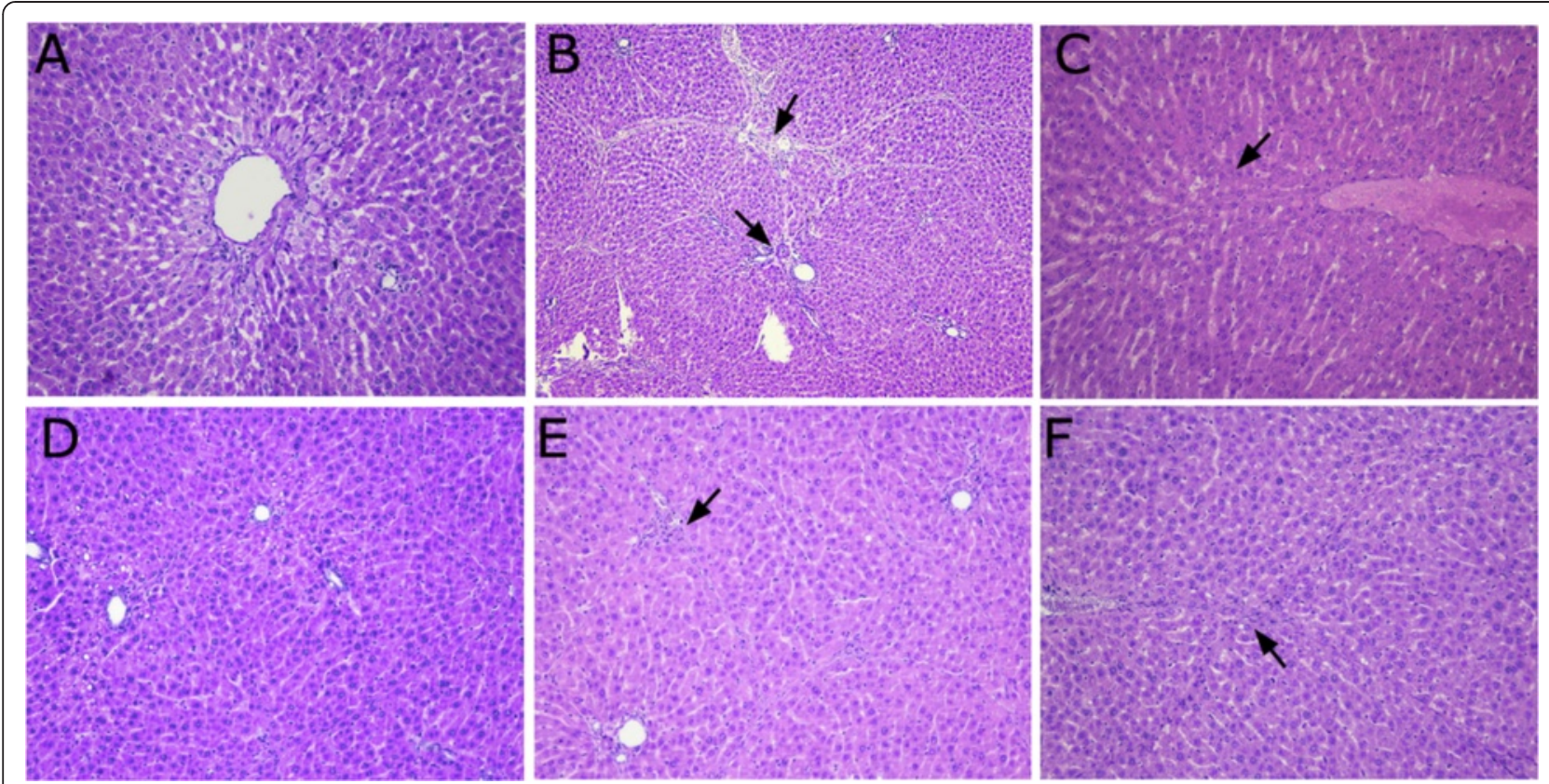

Fig. 2 H\&E staining in BSA-induced hepatic fibrosis rats (H\&E stain, magnification $\times 200$ ). a normal group; b model group; c BJRJ, 600 mg/kg; d CPhGs, $500 \mathrm{mg} / \mathrm{kg} ;$ e CPhGs, $250 \mathrm{mg} / \mathrm{kg} ; \mathbf{f} C P h G s, 125 \mathrm{mg} / \mathrm{kg}$

fibrosis, stimulating the production of extracellular matrix [19]. We showed that the level of TGF- $\beta_{1}$ increased in the model group in a manner consistent with the severity of liver fibrosis. The expression levels of TGF- $\beta_{1}$ in liver were consistent with serum TGF- $\beta_{1}$ levels. This indicates that CPhGs can significantly reduce liver fibrosis due to TGF- $\beta_{1}$ expression by participating in the synthesis and degradation of ECM.

The expression of collagen type I, collagen type III, and TGF- $\beta_{1}$ can detect the pathological process of hepatic fibrosis. Their expression levels in the treatment

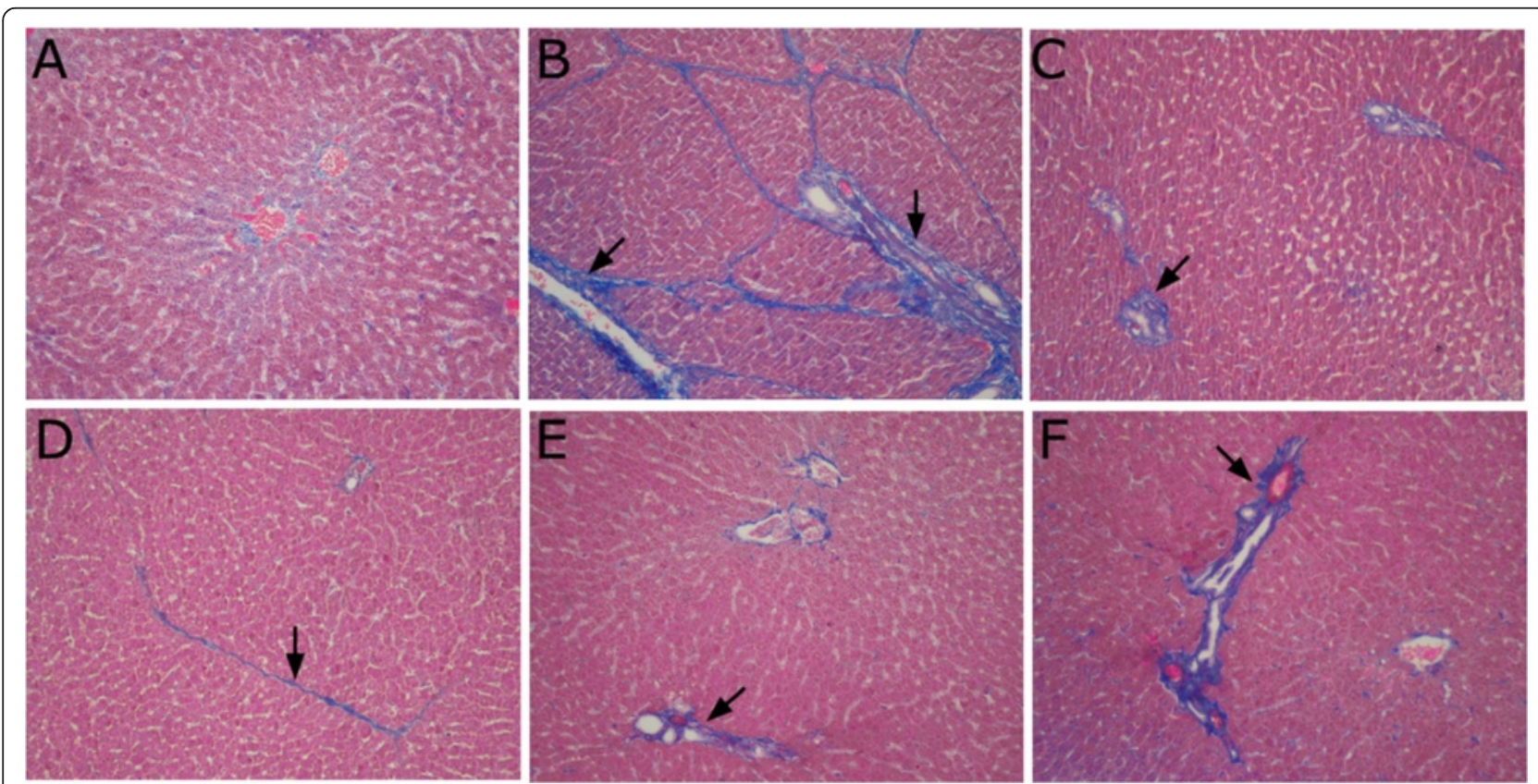

Fig. 3 Masson's trichrome staining in BSA-induced hepatic fibrosis in rats (Masson's trichrome stain, magnification × 200). a normal group; b model group; c BJRJ, 600 mg/kg; d CPhGs, 500 mg/kg; e CPhGs, 250 mg/kg; f CPhGs, 125 mg/kg 

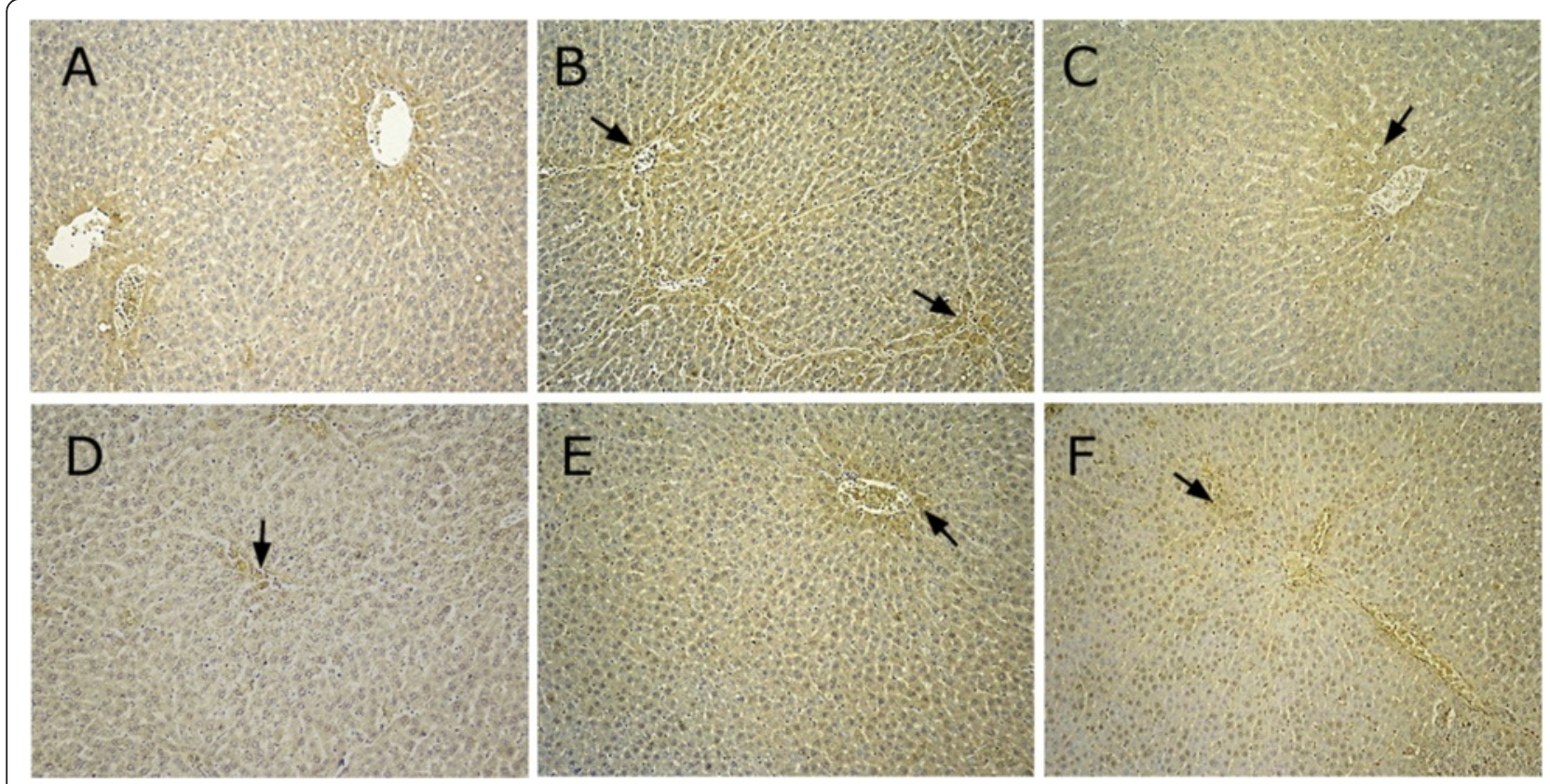

Fig. 4 Expression of collagen type I in BSA-induced hepatic fibrosis in rats (immunohistochemical staining, magnification $\times 200$ ). a normal group; b model group; c positive group; $\mathbf{d}$ CPhGs high dose group; e CPhGs middle dose group; $\mathbf{f}$ CPhGs low dose group

groups were significantly decreased, and illustrated that $\mathrm{CPhGs}$ can improve collagenase activity, maintaining the dynamic equilibrium of liver ECM synthesis and degradation, thus delaying and preventing the formation of liver fibrosis.

\section{NF-KB p65 and collagen I expression after drug intervention in HSC-T6 cells}

In order to characterize signals of hepatic fibrosis, two key regulatory genes in the liver were determined via RT-PCR assay. The data showed that tHSC-T6

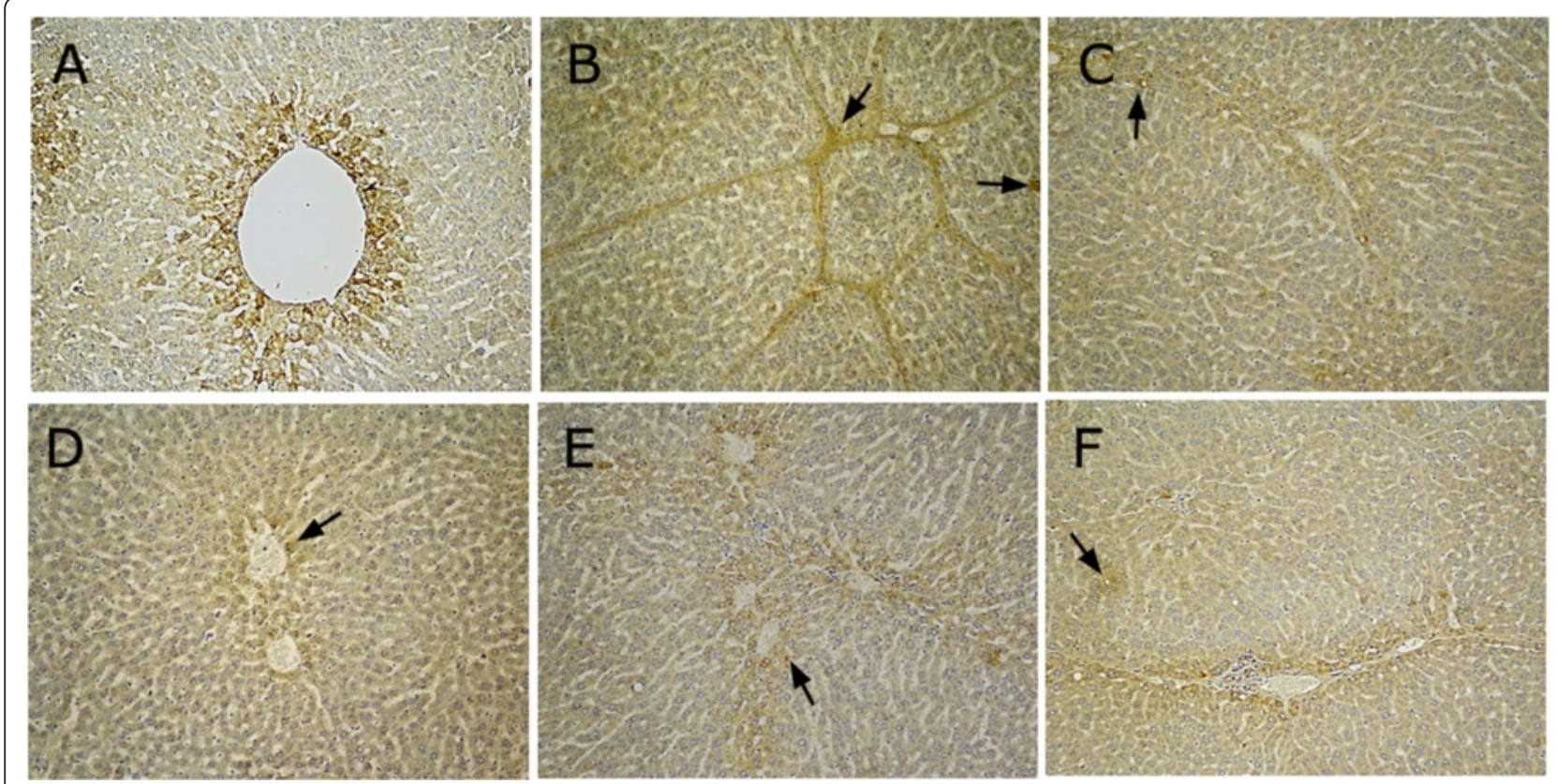

Fig. 5 Expression of collagen type III in BSA-induced hepatic fibrosis in rats (immunohistochemical staining, magnification $\times 200$ ). a normal group;

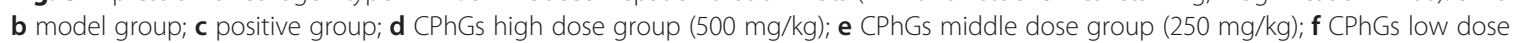
group $(125 \mathrm{mg} / \mathrm{kg})$ 


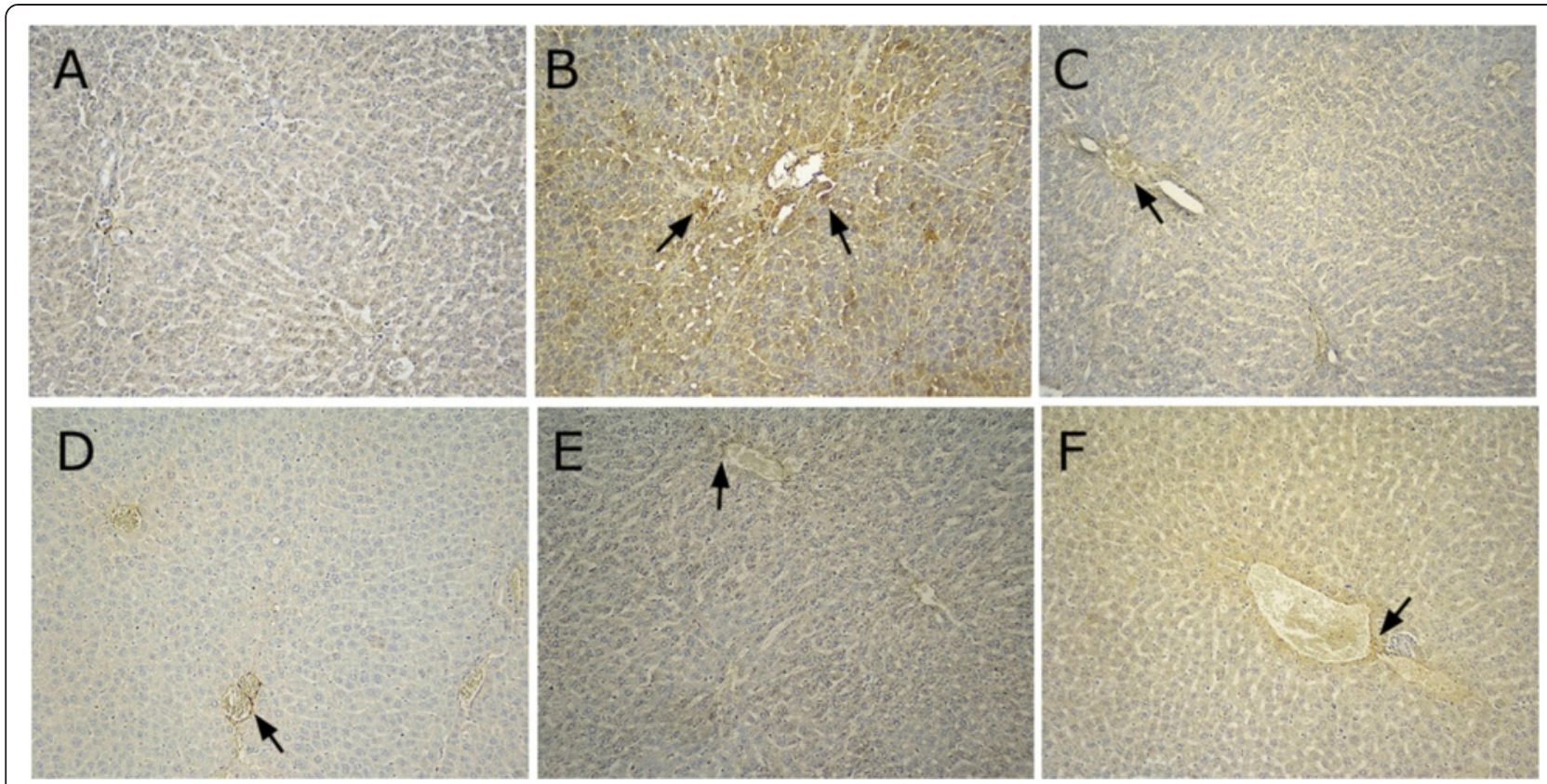

Fig. 6 Expression of TGF- $\beta_{1}$ in BSA-induced hepatic fibrosis in rats (immunohistochemical staining, magnification $\times 200$ ). a normal group; $\mathbf{b}$ model group; c positive group; d CPhGs high dose group (500 mg/kg); e CPhGs middle dose group (250 mg/kg); f CPhGs low dose group (120 mg/kg)

cells from the control group had lower levels of NF$\kappa \mathrm{B}$ and collagen type I mRNA. Conversely, TGF- $\beta_{1}$ induced HSC-T6 cells to markedly upregulate NF-kB $(P<0.01)$ and Col-I $(P<0.01)$ mRNA, with levels higher than those in the control group. In the presence of different concentrations of CPhGs, the results of NF-kB p65 $\left[P_{\mathrm{NF}-\mathrm{kB}}=0.001\right.$ for $100 \mathrm{ug} / \mathrm{ml}, P$ NF-kB $=0.002$ for $75 \mathrm{ug} / \mathrm{ml}, P_{\mathrm{NF}-\mathrm{kB}}=0.007$ for $50 \mathrm{ug} /$ $\mathrm{ml}$, and $P_{\mathrm{NF}-\mathrm{kB}}=0.012$ for $25 \mathrm{ug} / \mathrm{ml}$, respectively]

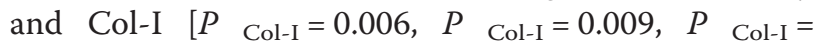

0.014, $P$ Col-I $=0.019$, respectively] showed reduced expressions of these mRNAs (Fig. 7).

\section{Western blot analysis of collagen I levels after drug intervention in HSC-T6 cells}

Figure 8 shows the collagen I protein expression levels in HSC-T6 cells of the different experimental groups. The collagen I protein expression level was significantly decreased in the various dose groups of CPhGs (100 ug/

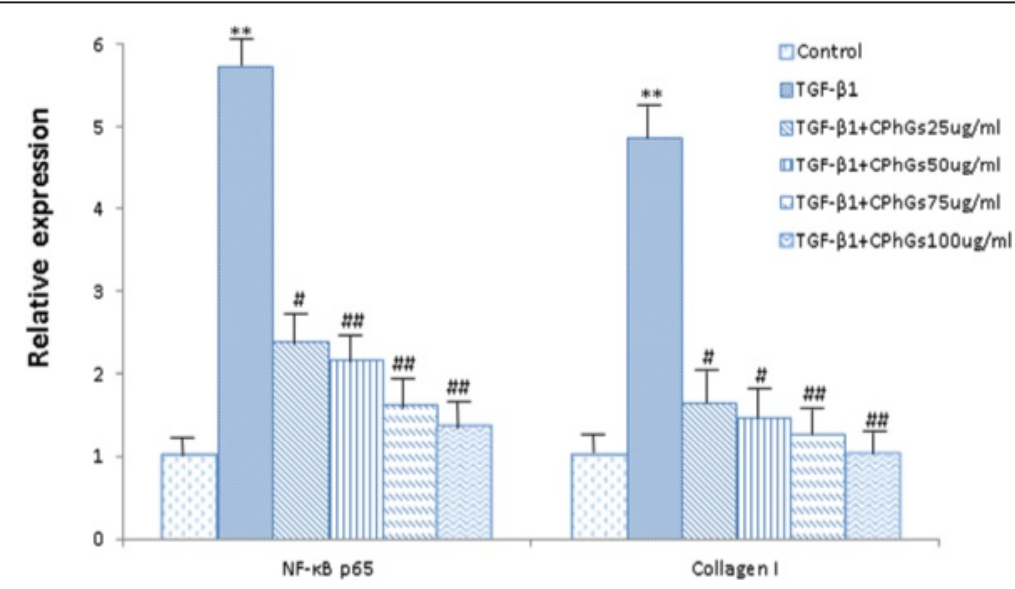

Fig. 7 CPhGs down-regulated the expressions of NF-KB and collagen I mRNA in HSC-T6 cells (RT-PCR assay). Data were analyzed via one-way ANOVA followed by Bonferroni post-tests. Results are expressed as the mean \pm SE. Notes the following: ${ }^{* *} P<0.01$ vs. control group; ${ }^{\#} P<0.05$ vs. TGF- $\beta_{1}$ induced; $\#$ $P<0.01$ vs. TGF- $\beta_{1}$ induced 


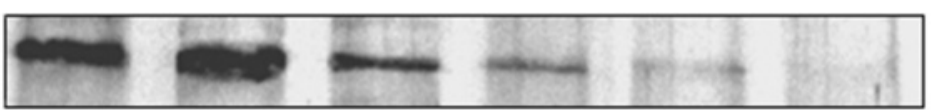

$130 \mathrm{kDa}$

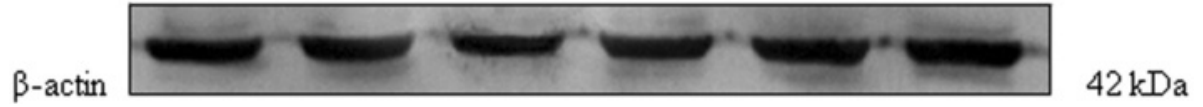

Fig. 8 Collagen I protein expression. Protein samples were subjected to electro-transfer to a PVDF membrane, incubated with primary antibodies and anti-rabbit secondary antibodies conjugated with AP. Lane 1: normal; lane 2: TGF- $\beta_{1}(5.0 \mathrm{ng} / \mathrm{mL})$; lane 3: TGF- $\beta_{1}+$ CPhGs $(25 \mathrm{ug} / \mathrm{ml})$; lane 4 : TGF- $\beta_{1}+$ CPhGs $(50 \mathrm{ug} / \mathrm{ml})$; lane 5: TGF- $\beta_{1}+$ CPhGs $(75 \mathrm{ug} / \mathrm{ml})$; lane 6: TGF- $\beta_{1}+$ CPhGs $(100 \mathrm{ug} / \mathrm{ml})$

$\mathrm{ml}, 75 \mathrm{ug} / \mathrm{ml}, 50 \mathrm{ug} / \mathrm{ml}$, and $25 \mathrm{ug} / \mathrm{ml}$ ) compared with the TGF- $\beta_{1}$ group.

\section{Discussion}

CPhGs is a phenylethanoid glycoside isolated and purified from rhizome of Cistanche, which is used as a traditional Chinese herbal medicine. In recent years, CPhGs had been shown to possess powerful ability to prevent liver injuries [20]. Therefore, we aimed to investigate whether CPhGs have inhibitory effects on hepatitis fibrosis by BSA induced hepatic fibrosis in rats. BJRG is commonly used as therapeutic drug for hepatic fibrosis in China. It is made from turtle shell. Radix paeoniae rubra, Cordyceps sinensis, Radix isatidis, and etc. have the effects of replenishing Qi and blood, relieving fatigue, softening nodes. In addition, previous studies show that it has the obvious function of blocking early liver fibrosis, inhibiting proliferation of fat storing cells, and reducing collagen synthesis [21]. Therefore, BJRG was used as a positive drug in this study.

The pathological changes of hepatic fibrosis in rats induced by BSA injections are similar to those in human portal cirrhosis [22]. CPhGs dose-dependently alleviated the degree of liver fibrosis and inhibited HSC transformation into myofibroblast-like cells, reduced the elevated levels of serum ALT, AST, HA, LN, CIV, TGF- $\beta 1$ and the liver index, and markedly suppressed expression of collagen I, collagen III and TGF- $\beta 1$ in liver tissue.

The stages of hepatic fibrosis are correlated with the serum levels of HA, LN and IV-C, which as markers may play a role in detecting the degree of hepatic fibrosis [23]. It has been reported that $\mathrm{HA}$ is the major resource of extracellular matrix. IV-C as the essential element of the basement membrane will be synthesized abundantly and deposit heavily in the earlier phases liver cirrhosis. The serum levels of LN and IV-C are the indexes of the turnover rate of the basement membrane and show the degree of fibrosis in the portal area and sinusoidal capillaries [24]. PC III is a marker in the diagnosis of hepatic fibrosis and early cirrhosis, but its sensitivity and specificity are not high, and there is no significant difference between the various stages of fibrosis in many references $[24,25]$. This study obtained a similar result.

In addition, the H\&E and Masson's trichrome stained section observations exhibit normal liver tissues with distinct hepatic lobules and hepatic sinusoids. The liver tissue structure in the model group was disordered, and the liver tissue and hepatic sinusoid were replaced by a large amount of connective tissue. However, significantly improvement was observed in the treatment groups compared with the model group.

Importantly, collagen type I and collagen type III expression play essential roles in the development of hepatic fibrosis, the blocking of which can prevent and treat hepatic fibrosis. Therefore, the generation and deposition in the liver tissue of collagen type I and collagen type III could serve as an important determinant of anti-hepatic fibrosis efficacy. TGF- $\beta_{1}$ is also an important profibrogenic cytokine in liver injury and it is biologically active with multiple pharmacological actions [26]. A balance among these actions is required to maintain tissue homeostasis. The aberrant expression of TGF$\beta_{1}$ is involved in the pathogenesis of liver diseases $[27,28]$. It is known that TGF- $\beta_{1}$ is a crucial cytokine that is involved in the early stages of liver fibrosis. Oxidative stress triggers TGF- $\beta_{1}$, resulting in the latter stimulating ECM production and deposition [29]. Therefore, one of the effective strategies to produce anti-hepatic fibrosis drug is to identify anti-TGF- $\beta_{1}$ agents. Immunohistochemical analysis showed that the expressions of collagen type I, collagen type III and TGF- $\beta_{1}$ could detect the pathological process of hepatic fibrosis. The expressions of the collagen type I, collagen type III and TGF- $\beta_{1}$ in the treatment groups are decreased, which were significantly lower in the high dose $\mathrm{CPhGs}$ treatment group in particular, and suggested that $\mathrm{CPhGs}$ is an effective collagen type I, collagen type III and TGF- $\beta 1$ inhibitor. Presumably, CPhGs can improve collagenase activity, maintaining the dynamic equilibrium of ECM synthesis and degradation, thus delaying and preventing the formation of liver fibrosis.

CPhGs not only could ameliorate BSA-induced hepatic fibrosis in rats, but also might be associated with inhibiting the activation of $\mathrm{HSC}$ in vitro. HSC activation is thought to represent the crucial step of fibrogenesis. In 
this study, the results illustrated that administration of CPhGs from 25 to $100 \mathrm{ug} / \mathrm{ml}$ remarkably attenuated the decreased NF- $\mathrm{kB}$ p65, collagen I mRNA expression, and collagen I protein expression in HSC.

NF- $\mathrm{KB}$ plays an important role in modulating the immune response to infection or stimuli [30]. Buildup of $\mathrm{NF}-\mathrm{KB}$ in liver cells can result in the recruitment of inflammatory cytokines/mediators, thus inducing fibrosis development $[31,32]$. Moreover, collagen is also a sensitive index that reflects the fibrosis level and accounts for about $50 \%$ of the total protein in fibrous liver [33]. As a result, we postulated that the molecular mechanism against hepatofibrosis is linked to CPhGs-mediated inactivation of NF- $\mathrm{kB}$ expression, in which the benefit contributes to synergistic roles of attenuating immunotoxicity and inflammation stress in BSA-lesioned liver tissue, further correcting dysmetabolism to ameliorate liver functions.

\section{Conclusions}

In conclusion, our studies indicate that $\mathrm{CPhGs}$ significantly attenuate the extent of hepatic fibrosis induced by BSA in rats. Its mechanism may at least partially be due to the inhibitory effect of CPhGs on the composition of ECM and stimulation of the degradation of ECM, and/ or by directly inhibition of the synthesis of collagen type I, collagen type III and the expression of TGF- $\beta_{1}$. Therefore, we expected that $\mathrm{CPhGs}$ can be used in health care products or in clinical medications for prevention of human liver fibrosis. Future studies are required to establish the efficacy of CPhGs as a potent anti-hepatic fibrosis drug.

\footnotetext{
Abbreviations

CPhGs: Phenylethanol glycosides from cistanche; BSA: Bovine serum albumin; HSC-T6: Hepatic stellate cells; Hyp: Hydroxyproline; BJRG: Compound Biejiarangan tablets; TGF- $\beta_{1}$ : Transforming growth factor $\beta_{1}$; ALT: Alanine aminotransferase; AST: Aspartate aminotransferase; HA: Hyaluronic acid; LN: Laminin; PC III: Type III precollagen; IV-C: Type IV collagen; NF-KB: Nuclear factor kappa-light-chain-enhancer of activated B cells; RT-PCR: Reverse transcriptase polymerase chain reaction; SDS-PAGE: Sodium dodecyl sulfate polyacrylamide gel electrophoresis.
}

\section{Competing interests}

The authors declare that they have no competing interests.

\section{Authors' contributions}

$T L, J Z, S P Y, L M, M T$ and SLZ conceived and designed the experiments. SPY, TL and JZ analyzed the data. SPY and JZ wrote the manuscript. TL, $L M$ and $J Z$ reviewed the manuscript. All authors read and approved the final manuscript.

\section{Acknowledgment}

This research was supported by National Natural Science Foundation of China (81260624). The authors would like to express their sincere thanks to Professor Tao Liu for his suggested improvements for the writing of this paper.

\section{Author details}

${ }^{1}$ Department of Toxicology, School of Public Health, Xinjiang Medical University, No. 393 Xinyi Road, Urumqi 830011Xinjiang Uyghur Autonomous
Region, China. ${ }^{2}$ Key Laboratory for Uighur Medicine, Institute of Materia Medica of Xinjiang, Urumqi 830004, China. ${ }^{3}$ No. 140 Xinhua South Road, Tianshan District, Urumqi 830000Xinjiang Uyghur Autonomous Region, China.

Received: 6 August 2015 Accepted: 24 November 2015 Published online: 09 December 2015

\section{References}

1. Cohen-Naftaly M, Friedman SL. Current status of novel antifibrotic therapies in patients with chronic liver disease. Ther Adv Gastroenterol. 2011;4(6):391-417.

2. Puche JE, Saiman Y, Fiedman SL. Hepatic stellate cells and liver fibrosis. Compr Physiol. 2013;3(4):1473-92.

3. Hernandez-Gea V, Friedman SL. Pathogenesis of liver fibrosis. Annu Rev Pathol. 2011;6:425-56.

4. Sohrabpour AA, Mohamadnejad M, Malekzadeh R. Review article: the reversibility of cirrhosis. Aliment Pharmacol Ther. 2012;36(9):824-32.

5. Raven PH, Zhang LB, Ventenat O. Chinese academy of sciences. 23rd ed. China: Editorial Committee of Flora of China; 2013. p. 1-16.

6. Chinese Pharmacopoeia Commission of Sanitary Ministry of People's Republic of China. Chinese pharmacopoeia, Part 1. China: Chemical Industry Publishing House; 2010. p. 126.

7. Yan GH, Tian JH, Long BW, Li N. Research progress of phenylethanol glycosides from Cistanche tubulosa. Central South Pharm. 2012;10:692-5.

8. Li J, Huang D, He L. Effect of roucongrong (Herba Cistanches Deserticolae) on reproductive toxicity in mice induced by glycoside of Leigongteng (Radix et Rhizoma Tripterygii). J Tradit Chin Med. 2014;34(3):324-32.

9. Xing $Y$, Liao J, Tang $Y$, Zhang $\mathrm{P}$, Tan $\mathrm{C}, \mathrm{Ni}$ H, et al. ACE and platelet aggregation inhibitors from Tamarix hohenackeri Bunge (host plant of Herba Cistanches) growing in Xinjiang. Pharmacogn Mag. 2014;10(38):111-7.

10. Jia Y, Guan Q, Jiang Y, Salh B, Guo Y, Tu P, et al. Amelioration of dextran sulphate sodium-induced colitis in mice by echinacoside-enriched extract of Cistanche tubulosa. Phytother Res. 2014;28(1):110-9.

11. Wong HS, Ko KM. Herba Cistanches stimulates cellular glutathione redox cycling by reactive oxygen species generated from mitochondrial respiration in H9c2 cardiomyocytes. Pharm Biol. 2013;51(1):64-73.

12. Zhang SJ, Liu L, Yu JY. A RP: A RP-HPLC method for simultaneous determination of echinacoside and acteoside in Herbe Cistanches. Chin Pharm J 2004; 39(10): 740-741.

13. Zhu QG, Fang BW, Zhu QN, Wu HS, Fu QL. The study of the immunity liver fibrosis animal model induced by bovine serum albumin. Chin J Pathol. 1993;22:121-2

14. Qin DM, Wen ZP, Nie YR, Yao GM. Effect of cichorium glandulosum extracts on CCl4-induced hepatic fibrosis. Iran Red Crescent Med J. 2013;15, e10908.

15. Niu HM, Zeng DQ, Long CL, Peng YH, Wang YH, Luo JF, et al. Clerodane diterpenoids and prenylated flavonoids from Dodonaea viscosa. J Asian Nat Prod Res. 2010;12(1):7-14.

16. Li WW, Song XW, Wang HW, Shen BS, Wang QC. Correlation of NF-KB and pathological staging of liver fibrosis in patients with chronic hepatitis B. Chin J Immunol. 2013;29(3):251-4.

17. Zhang GL, Shi XF, Ran CQ, Xu M, Zhu ZJ. Effects of total saponins of panax notoginseng against liver fibrosis in rats. Acta Academiae Medicinae Militaris Tertiae. 2007;29:2212-4

18. Rossi O, Maggiore L, Necci F, Koberling O, MacLennan CA, et al. Comparison of colorimetric assays with quantitative amino acid analysis for protein quantification of generalized modules for membrane antigens (GMMA). Mol Biotechnol. 2015;57(1):84-93.

19. Dang SS, Li YP. Advances in understanding the role of transforming growth factor- $\beta 1$ in the pathogenesis of liver fibrosis. Shijie Huaren Xiaohua Zazhi. 2010;18:1631-6.

20. Zhao J, Liu T, Ma L, Yan M, Zhao Y, Gu Z, et al. Protective effect of acteoside on immunological liver injury induced by Bacillus Calmette-Guerin plus lipopolysaccharide. Planta Med. 2009;75(14):1463-9.

21. Yang FR, Fang BW, Lou JS. Effects of Fufang Biejia Ruangan pills on hepatic fibrosis in vivo and in vitro. World J Gastroenterol. 2013;19(32):5326-33.

22. Liu P, Fang BW, Liu C. The role of transforming growth factor $\beta 1$ and its receptor in immunological induced liver fibrogenesis in rats and effect of cordyceps polysaccharide on them. Chin J Hepatol. 1998;6:232-3.

23. Xu GG, Luo CY, Wu SM, Wang CL. The relationship between staging of hepatic fibrosis and the levels of serum biochemistry. HBPD INT. 2002;1:246-8. 
24. Liu J, Wang JY, Lu Y. Serum fibrosis markers in diagnosing liver fibrosis. Chin J Intern Med. 2006;145:475-7.

25. Li CZ, Wan MB, Zeng MD, Mao YM, Fan ZP, Cao AP, et al. A preliminary study of the combination of noninvasive parameters in the diagnosis of liver fibrosis. Chin J Hepatol. 2001;9:261-3.

26. Chen YL, Li ZY. The relationship between TGF- $\beta 1$, PDGF-BB, CTGF and chronic hepatitis B with fibrosis. Chin J Diffic Compl Cas. 2010;9:19-20.

27. Sferra R, Vetuschi A, Catitti V, Ammanniti S, Pompili S, Melideo D, et al. Boswellia serrata and Salvia miltiorrhiza extracts reduce DMN-induced hepatic fibrosis in mice by TGF-beta1 downregulation. Eur Rev Med Pharmacol Sci. 2012;16(11):1484-98.

28. Liu L, Li XM, Chen L, Feng Q, Xu LL, Hu YY, et al. The effect of Gypenosides on TGF- $\beta 1 /$ Smad pathway in liver fibrosis induced by carbon tetrachloride in rats. Intern J Integr Med. 2013;1:1-6.

29. Zhang BJ, Xu D, Guo Y, Ping J, Chen LB, Wang H. Protection by an antioxidant mechanism of berberine against rat liver fibrosis induced by multiple hepatotoxic factors. Clin Exp Pharmacol Physiol. 2008;35(3):303-9.

30. Tornatore L, Thotakura AK, Bennett J, Moretti M, Franzoso G. The nuclear factor kappa B signaling pathway: integrating metabolism with inflammation. Trends Cell Biol. 2012;22(11):557-66.

31. Luedde T, Schwabe RF. NF-KB in the liver-linking injury, fibrosis and hepatocellular carcinoma. Nat Rev Gastroenterol Hepatol. 2011;8(2):108-18.

32. Petrasek J, Csak T, Szabo G. Toll-like receptors in liver disease. Adv Clin Chem. 2013:59:155-201.

33. Wang $Y$, Cheng $M$, Zhang $B$, Nie $F$, Jiang $H$. Dietary supplementation of blueberry juice enhances hepatic expression of metallothionein and attenuates liver fibrosis in rats. PLoS One. 2013;8, e58659.

\section{Submit your next manuscript to BioMed Central and we will help you at every step:}

- We accept pre-submission inquiries

- Our selector tool helps you to find the most relevant journal

- We provide round the clock customer support

- Convenient online submission

- Thorough peer review

- Inclusion in PubMed and all major indexing services

- Maximum visibility for your research 